\title{
Cloning, Characterization, and Expression of the Nitric Oxide-Generating Nitrite Reductase and of the Blue Copper Protein Genes of Achromobacter cycloclastes
}

\author{
Jang-Yi Chen, ${ }^{*}$ Wei-Chao Chang, ${ }^{*}$ Tschining Chang, $\dagger$ Wen-Chang Chang, ${ }^{*} \uparrow$ Ming-Yih Liu, $\ddagger$ \\ William J. Payne, $\S$ and Jean LeGall $\$ 1$ \\ *Institute of Biochemical Sciences, National Taiwan University, Taipei, Taiwan; †Institute of Biological Chemistry, \\ Academia Sinica, Taipei, Taiwan; and $\$$ Departments of Biochemistry and Molecular Biology and \$Microbiology, \\ University of Georgia, Athens, Georgia
}

Received January 11, 1996

The nitrite reductase (NIR) and blue copper protein (BCP) genes have been cloned from Achromobacter cycloclastes and characterized. NIR gene encodes a protein of 378 amino acid residues including a putative signal peptide of 37 residues. BCP gene encodes a protein of 148 residues with a 24-residue signal peptide. The DNA-derived amino acid sequence of NIR is in complete agreement with that from Edman degradation and the DNA coding sequence of BCP is also consistent with its partial N-terminal amino acid sequence. Both genes contain their own FNR box in the $5^{\prime}$ upstream region and a TA-rich region that could be the transcription start site. These two genes are separated by at least $10 \mathrm{~kb}$. Based on these observations it is very likely that these two genes, although functionally related, are regulated independently. Both proteins could be expressed in E. coli, and both of the expressed proteins could be recognized by their respective antisera. The expressed NIR demonstrates full enzymatic activity. The similarity of both proteins to the counterparts from Alcaligenes faecalis $S-6$ is discussed. (c) 1996 Academic Press, Inc.

Nitrite reductase (NIR) is one of the enzymes involved in the alternative respiration system of the denitrifying bacteria. This copper-containing enzyme transfers electrons in the denitrifying pathway: $\mathrm{NO}_{3} \rightarrow \mathrm{NO}_{2} \rightarrow \mathrm{NO} \rightarrow \mathrm{N}_{2} \mathrm{O} \rightarrow \mathrm{N}_{2}$ (1), in which it reduces nitrite ion to nitric oxide. NIR receives electrons from the azurin-like blue copper protein $(\mathrm{BCP})(2,3)$. Both proteins have been purified from several organisms. Their crystal structures have also recently been determined $(4,5)$. The crystal structure of NIR is a trimer composed of three identical subunits. Each subunit contains one type I copper atom, and there are three type II copper atoms trapped in the space between the subunits. The BCP contains only one type I copper. In Alcaligenes faecalis, the electrons are transferred from the type I copper of the pseudoazurin to the type I copper then to type II copper within NIR (6). However, the exact protein-protein interaction between BCP and NIR, the mechanism of the electron flow from the environment to $\mathrm{BCP}$, and the details of the $\mathrm{NO}_{2}{ }^{-}$reduction within NIR still remain uncertain. As part of the continuing effort to gain a clearer understanding of the components of these reactions, we describe here the cloning and characterization of the nucleotide sequences of the NIR and the BCP genes from Achromobacter cycloclastes and their expression in Escherichia coli.

\section{MATERIALS AND METHODS}

Bacterial strains and plasmids. Achromobacter cycloclastes IAM1013 was used to construct a genomic library for the screening of NIR and BCP genes. E. coli LE392 was used for genomic DNA cloning. E. coli JM109 used for plasmid cloning and sequencing was from Promega Inc. E. coli. strain M15 (PREP4), which derived from strain K12 was purchased from Qiagen Inc. and used for gene expression. The plasmids, pGemT, pGem3zf(+) (Promega) and pUC19, were used as cloning vector, and plasmid pQE30 (Qiagen Inc.) was used as expression vector.

Media. A. cycloclastes IAM1013 was grown anaerobically at $30^{\circ} \mathrm{C}$ in the following medium (per liter): nutrient broth,

${ }^{1}$ To whom correspondence should be addressed. 
$2.3 \mathrm{~g}$; yeast extract, $1.2 \mathrm{~g}$; glycerol, $5 \mathrm{ml} ; \mathrm{NaCl}, 3 \mathrm{~g}$; and potassium nitrate, $0.5 \mathrm{~g}$. E. coli. strains were cultured in L-broth medium aerobically at $37^{\circ} \mathrm{C}$. The concentration of ampicillin used for selection was $50 \mu \mathrm{g} / \mathrm{ml}$; for blue/white colony selection. IPTG, $0.5 \mathrm{mM}$, and X-Gal, $40 \mu \mathrm{g} / \mathrm{ml}$ (final concentration), were added to the medium. For expression of the cloned NIR protein and BCP under control of E. coli, T5 promotor, two lac operator sequences and 2mM IPTG were added.

Chemicals and Enzymes. All of the DNA modification enzymes and restriction endonucleases used were purchased from Boehringer Mannheim GmbH or Promega Inc. $\left[\alpha-{ }^{32} \mathrm{P}\right] \mathrm{dATP}$ and $\left[\alpha{ }^{35} \mathrm{~S}\right] \mathrm{dATP}$ were from Amersham Inc. The nucleotide sequencing kits were the products of USB Inc. The recombinant gene expression and protein purification kits were purchased from Qiagen Inc.

Genomic library construction. All the methods used were as described (7). In general, genomic DNA of A. cycloclastes was partially digested with Sau3AI restriction endonuclease, size-fractionated and then ligated with EMBL III vector. After in vitro packaging, it was used to transfect $E$. coli strain LE 392.

Cloning of NIR and BCP genes. Two primers were designed based on the amino acid sequence of NIR: forward primer corresponding to amino acids at positions 73 to 81: 5'ATGGTNGTNCAYGARAAYGAYTAYG3', reverse primer corresponding to amino acids at positions 329 to 322: 5'TCRTCRTTCCAYTCNCCNGTNAC3'. A polymerase chain reaction (PCR) was performed using the above primers and genomic DNA of A. cycloclastes as template to produce a DNA fragment of $750 \mathrm{bp}$. After subcloning and sequencing to confirm its identity, this fragment was used to screen the genomic library. For the cloning of BCP gene, the same procedure was repeated, except the primers were designed based on their partial amino acid sequence as follows: forward primer corresponding to amino acids at positions 1 to 7: 5'GCNGAYTTCGARGTBCAYATG3', reverse primer corresponding to amino acids 43 to 37: 5'YTCVACGTTCTTNCCCTTRTC3'. The product of $129 \mathrm{bp}$ fragment from a PCR was subcloned, sequenced and used as probe for screening of BCP gene.

Expression of BCP and NIR gene in E. coli. For NIR gene, a pair of synthetic oligonucleotides were synthesized as primer: forward primer (NP1) beginning with the enterokinase cutting site (DDDDK) coding sequence followed by the codons of mature NIR protein; the reverse primer (NP2) containing the sequence of $3^{\prime}$ end and stop codon of NIR gene. After PCR amplification, the products were phosphorylated in order to ligate with pUC19 polylinker region on HincII site, then cleaved by BamHI and Hind III and ligated with pQE30 to produce NIR gene expression vector pQNIR. For BCP gene: forward primer (BP1) contained not only enterokinase cutting site coding sequence but also a Bam HI recognition sequence before the mature BCP gene. The reverse primer (BP2) contained a Hind III recognition sequence after $3^{\prime}$ end coding sequence. The constructed vectors were checked by sequencing of the junction regions and transformed to $E$. coli strain M15. Cells carrying $\mathrm{pQBC} 3$ and $\mathrm{pQNIR}$ were precultured in LB medium, then IPTG was added to a final concentration of $2 \mathrm{mM}$ and incubated for $5 \mathrm{hrs}$. The cells were harvested and lysed. The cell extract was passed through Ni-NTA(nitrilotri-acetic acid) resin to the fused recombinant proteins which contain $6 \times$ His tag. The fused protein purified could be cut by enterokinase after the sequence DDDDK amino acid sequence to release native products of NIR or BCP.

Immunological techniques. Both anti-NIR and anti-BCP sera were obtained by immunizing New Zealand White rabbits with native NIR or BCP by surgical intrasplenic immunization according to the method of Hong et al. (8). Blood samples were taken between the fourth week and the tenth week. The antisera were used without further purification. Western blotting was carried out after SDS PAGE according to Bjerrum et al. (9). The membrane was first treated with rabbit anti-NIR or anti-BCP serum (1:5000) and followed by alkaline phosphatase conjugated goat anti-rabbit total Ig or IgG, then developed by incubation with nitroblue-tetrazolium and 5-bromo-4-chloro-3-indoyl-phosphate (Bcip).

\section{RESULTS AND DISCUSSIONS}

A genomic library of A. cycloclastes has been constructed with an efficiency of $7.5 \times 10^{5} \mathrm{pfu} /$ $\mu \mathrm{g}$ DNA. Both NIR and BCP genes are found inside this library and the nucleotide sequences for NIR and BCP genes are shown in Fig. 1,A and Fig. 1,B, respectively. There are three open reading frames containing the NIR structure sequence (Fig. 1,A). The protein deduced from the longest reading frame is composed of 378 amino acid residues with a putative signal peptide of 37 residues. The deduced amino acid sequence following the putative signal peptide is in complete agreement with that described from Edman degradation. Comparison with the NIR from A. faecalis reveals that the major difference is around this leader peptide. The mature proteins of these two NIR share a sequence homology of $81 \%$.

The longest open reading frame in BCP gene (Fig. 1,B) encodes a protein of 152 amino acid residues. The mature protein starting from Ala29 to the C-terminal has $99.2 \%$ homology to that of pseudoazurin (10) with only one difference at Gln 89 which is a Glu in pseudoazurin. There are three methionine codons before Ala29. The Met5 is preceded by a ribosome binding sequence (SD sequence). Besides, the peptide from Met5 to Ala28 is a typical signal peptide as reported by Duffaud et al. (11): Positively charged amino acid (Lys10) at the N-terminal, hydrophobic core to form a helix (Gly12 to Ala24) and small amino acid (Ala) around the processing site at the 
A tgcaggtcaacggatcgcccagagggeggctgcgaggaagaacggccggaagccatagga

gaagagcaccgggccggtggtcgagag tcgcgcggaatgccgccgctcggtt tcggtct $t$

a tcaatctg tccaacatgg tcg tg t tcctcg tcg tgcgtcct tgcggact tgcggatgag

FNR box

gct tgatctatcaatgggt tcgaaggccetct t gcgaaaacgcaag tatcgetgcccgg tcggaccgccgacg tcgcaagggctaaagaaaagcgatctcctcgcaacgatt tgt tcca agacaaagacgagat tcgtctgtggt tc tact tctctag tgactgctgggggaccggt tg $T A$

gtcgagaccggagg tgaggccgcccaagtcgcgecgcccaccctaactcgttgaa tacag

SD

gcgcgt t tcgcagaagccaa tcccggccgctggaacgcgccgaaggagagcaaga tgact

gaacaact tcagatgacccgccggacgatgct tgccggcgctgccctggcgggcgcggtt

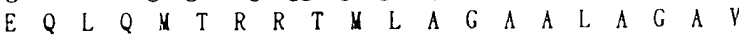
gcgccgct tctccacaccgctcaggcgcatgccgctggcgctgccgcgGCAGCCGCTCCT

A $P$ P L L H GCCCCCGTCGATATCTCGACCCTCCCTCGCGTCAAGGTCGACCTCGTCAAGCCGCCTTTC $\begin{array}{llllllllllllllllllll}A & P & V & D & I & S & T & L & P & R & V & K & V & D & L & V & K & P & P & F\end{array}$ GTGCACGCCCATGACCAGGTCGCCAAGACCGGACCGCGCGTCGTCGAGTTCACCATGACG

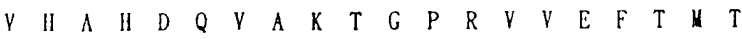
ATCGAGGAAAAGAACCTGGTGATCGACCGCGAGGGCACTGAGATCCACGCGATGACCTTC $\begin{array}{llllllllllllllllllll}I & E & E & K & K & L & V & I & D & R & E & G & T & E & I & H & A & H & T & F\end{array}$ MACGTTCGGTGCCTGGTCCCCTGATGGTGGTGCATGAGAACGACTATGTTGAACTGCGG

103 N $G$ G CTGATCAACCCTCACACCAACACGTTGCTGCACAACATCGACTTCCACGCCGCAACCGGT

$\begin{array}{lllllllllllllllllllll}123 & L & I & N & P & D & T & N & T & L & L & H & N & I & D & F & \| & A & A & T & G\end{array}$ GCGCTCGGCGGCGGGGCGCTCACCCAGGTGAACCCGGGCGAGGAAACCACGCTTCGTTTC

$\begin{array}{lllllllllllllllllllll}143 & A & L & G & G & G & \Lambda & L & T & Q & Y & N & P & G & E & E & T & T & L & R & F\end{array}$ AAGGCGACCAAGCCCGGCGTCTTCCTCTACCATTGCGCCCCGGAGGGCATGGTGCCCTGG $\begin{array}{llllllllllllllllllll}K & A & T & K & P & G & \vee & F & \vee & Y & H & C & A & P & E & G & Y & \vee & P & \end{array}$ CACGTCACCTCGGGCATGAACGGCGCCATCATGGTGCTGCCGCGCGACGGACTGAAGGAC

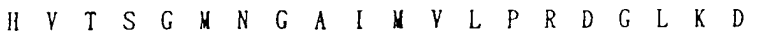
GAGAAGGGCCAGCCGCTGACGTACGACAAGATCTACTATGTCGGCGAGCAGGACTTCTAC $\begin{array}{llllllllllllllllllll}E & K & G & Q & P & L & T & Y & D & K & I & Y & Y & V & G & E & Q & D & F & Y\end{array}$ GTGCCGAAGGACGAGGCCGGGAACTACAAGAAGTACGAAACCCCCGCCGAAGCCTATGAA $\begin{array}{llllllllllllllllllll} & P & K & D & E & A & G & N & Y & K & K & Y & E & T & P & G & E & A & Y & E\end{array}$ GATCCTGTCAAGGCGATGCGCACGCTCACCCCGACCCACATCGTCTTCAACGCTGCGGTC $\begin{array}{llllllllllllllllllll}D & A & V & K & A & N & R & T & L & T & P & T & H & \text { I } & \text { Y } & F & N & G & A & V\end{array}$ GGCGCGCTGACCGGCGACCATGCTTTGACTGCGCCCGTCGGCGAGCGTCTGCTCGTCGTC $\begin{array}{llllllllllllllllllll}G & A & L & T & G & D & H & \Lambda & L & T & A & A & V & G & E & R & V & L & V & V\end{array}$ CATTCGCAGGCCAACCGCGAT ACGCGGCCGCACCTGATCGGCGGGCATGGTGACTATGTC $\begin{array}{llllllllllllllllllll}\| & S & Q & A & N & R & D & T & R & P & H & \text { L } & \text { I } & G & G & H & H & D & Y & V\end{array}$ TGGGCG $\triangle C C G G C A \Lambda G T T C C G C A \Lambda C C C G C C G G \Lambda T C T C G \Lambda C C A G G \Lambda A \Lambda C C T G G C T C A T T C C G$

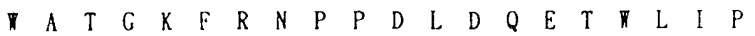
GGCGGAACCGCGGGCGCTGCCTTCTACACCTTCCGCCAGCCGGGTGTGTACCCCTACGTC $\begin{array}{llllllllllllllllllll}G & G & T & A & G & A & A & F & Y & T & F & R & Q & P & G & Y & Y & A & Y & V\end{array}$ AACCACA СCTGATCGAGGCGTTCGAGCTGGGTCCCGCCGCСCACTTCAAGGTGACCCGC

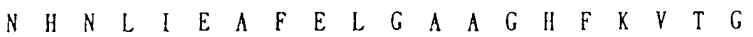
GAATGGAMCGATGATCTGATCACATCGCTCGTCAAGCCGGCGTCGATCTAGccgg tgaca

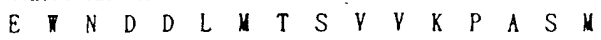

gcggatgatcg tggggccgcgctcacaggcacccagccgcgaacaaaggcacgcgct tg ccggcgct tccccggagacct tccatgcccaccaccaagaaaactgcggt t tccgtcctc tcgctagcagcaccgg tcg tcct t t tggcggcaatcggcggcgtgct t tcggcgaagg tg gggctg t tcgacga tctcaaggacggca tcgatccg tcga tcaggccgccgg tgaccgtg acgatcgcgccgcacaga tgagctatcgggcggagggacact $t$

FIG. 1. Nucleotide sequence of $\operatorname{NIR}(\mathrm{A})$ and $\mathrm{BCP}(\mathrm{B})$ genes. Nucleotides and amino acids are numbered at the right and left margin, respectively. The asterisk indicates the $\mathrm{N}$-terminal of the mature protein. The putative gene regulatory elements: FNR box; SD sequence and TA-rich region (see text) are underlined. 


\begin{tabular}{|c|c|}
\hline B & gttcctgctcatgcggtcat taatataggaatcctatgtattgtcaatgccga \\
\hline & FNR box \\
\hline & agcggcgcgaat t tgacgcgcatcaaag tggagggggcgtctcaggct taatcctct tct \\
\hline & SD \\
\hline & cgaacaaccgagcacgggctggtcgctcaaatggagaagacgatgt tgaatgcaatcaag \\
\hline 1 & HE K T N L N $A I K$ \\
\hline & agcggatt tggtatcgcgatcgcggcaatgctggtcgccgcaccggcagccgccGCGCAC \\
\hline 11 & 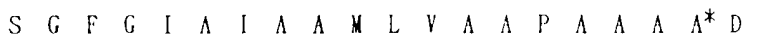 \\
\hline & TTCGAAGTGCACATGCTGAACAAGGGCANGGACGGCGCGATGCTTTTCGAGCCGGCGTCG \\
\hline 31 & 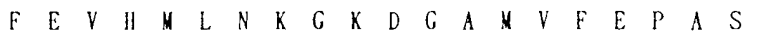 \\
\hline & 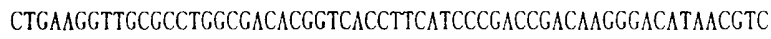 \\
\hline 51 & $\begin{array}{llllllllllllllllllll}\mathrm{L} & \mathrm{K} & V & \mathrm{~A} & \mathrm{P} & G & \mathrm{D} & \mathrm{T} & \mathrm{V} & \mathrm{T} & \mathrm{F} & \mathrm{I} & \mathrm{P} & \mathrm{T} & \mathrm{D} & \mathrm{K} & \mathrm{G} & \mathrm{H} & \mathrm{N} & \mathrm{V}\end{array}$ \\
\hline & GAAACCATCAAGGGCATGATCCCCGATCGCGCCGAGGCCTTCAMAAGCAAGATCAATGAA \\
\hline 71 & 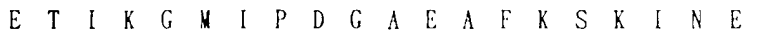 \\
\hline & AACTACAAGGTGACTTTCACGGCGCCGGGCGTCTACGGCGTAAAGTGCACGCCGCACTAC \\
\hline 91 & 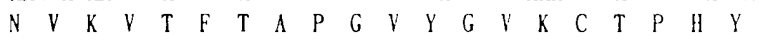 \\
\hline & GGCATGGGCATGGTCGGCGTCGTTCAGGTCGGCGATGCGCCGGCCAACCTGGAAGCGGTC \\
\hline 1 & 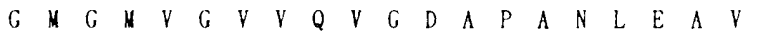 \\
\hline & AAGGGAGCGAAGAACCCGAAGAAGCCTCAGGAACGCCTGGACGCAGCCCTCGCGGCCCTC \\
\hline 1 & 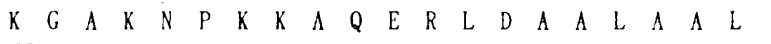 \\
\hline & GGTAACTAAgcgact tc tagcgct tcggagcggggg tggggacaggccgetcctggegtc \\
\hline & G N \\
\hline & tgcgcactgggtgaggcgcgggccgatcatgcggaaccaatgcgaacgat tcgcgt tggt \\
\hline & tccgcatggatcagaat \\
\hline
\end{tabular}

FIG. 1-Continued.

60

C-terminal. Therefore, the entire coding sequence in the BCP gene should begin from the second ATG, and have 148 amino acid residues including the signal peptide of 24 residues. The partial $\mathrm{N}$-terminal sequence also matches completely with the DNA-derived sequence. When the sequence was compared with its counterpart in A. faecalis $S-6$, the homology was only $66 \%$, and even lower, $53.5 \%$, with that of Pseudomonas ami (12). This is quite different from the case of NIRs where a high degree of homology is found. Since BCPs are proposed to have similar function as electron donor for NIR, it might mean that the structure is more flexible for the pseudoazurin/BCP than that of NIR. In fact, those essential residues for maintaining the function of the BCP, such as copper binding residues and hydrophobic face surrounded with lysine-residue ring, are conserved (13).

Both BCP and NIR genes contain the FNR box in their 5' upstream region (Fig. 1,A and B), a structure that could be regulated, as it has been suggested, by the aerobic-anaerobic shift (14). On the other hand, we could not find the typical Pribnow box in either gene. Instead, a TA-rich region around base 110, TTAAT (Fig. 1,B), of the BCP and around base 412, TTGAATA (Fig. 1,A), of the NIR gene were found. Since each of the two genes contains its own FNR box and the restriction mapping shows that they are separated by at least $10 \mathrm{~kb}$ (data not shown), it is suggested that those TA-rich regions could be the transcription start sites. If so, then these two genes would not form an operon such as that found in E. coli (15).

Both genes could be expressed in E. coli after IPTG induction (Fig. 2,A). Most of the proteins were present in soluble fraction during the purification process (data not shown). The expressed proteins were easily purified with a $\mathrm{Ni}^{+2}$-NTA resin affinity column because of the $6 \times$ His tag present at the N-terminal of the fusion protein. The $6 \times$ His tag could also be removed by enterokinase to release the native protein. The N-terminal sequencing confirmed that the expressed NIR and $\mathrm{BCP}$ are identical to the native proteins. The absorption spectrum of recombinant $\mathrm{BCP}$ in the oxidized state is the same as that of the native $\mathrm{BCP}$, which could also be easily reduced by an agent such as dithionite. The recombinant NIR shows the same optical absorption spectrum as the native protein and has fully enzyme activity (data not shown). The expressed proteins were recognized by the respective antisera as shown in Fig. 2, B. 

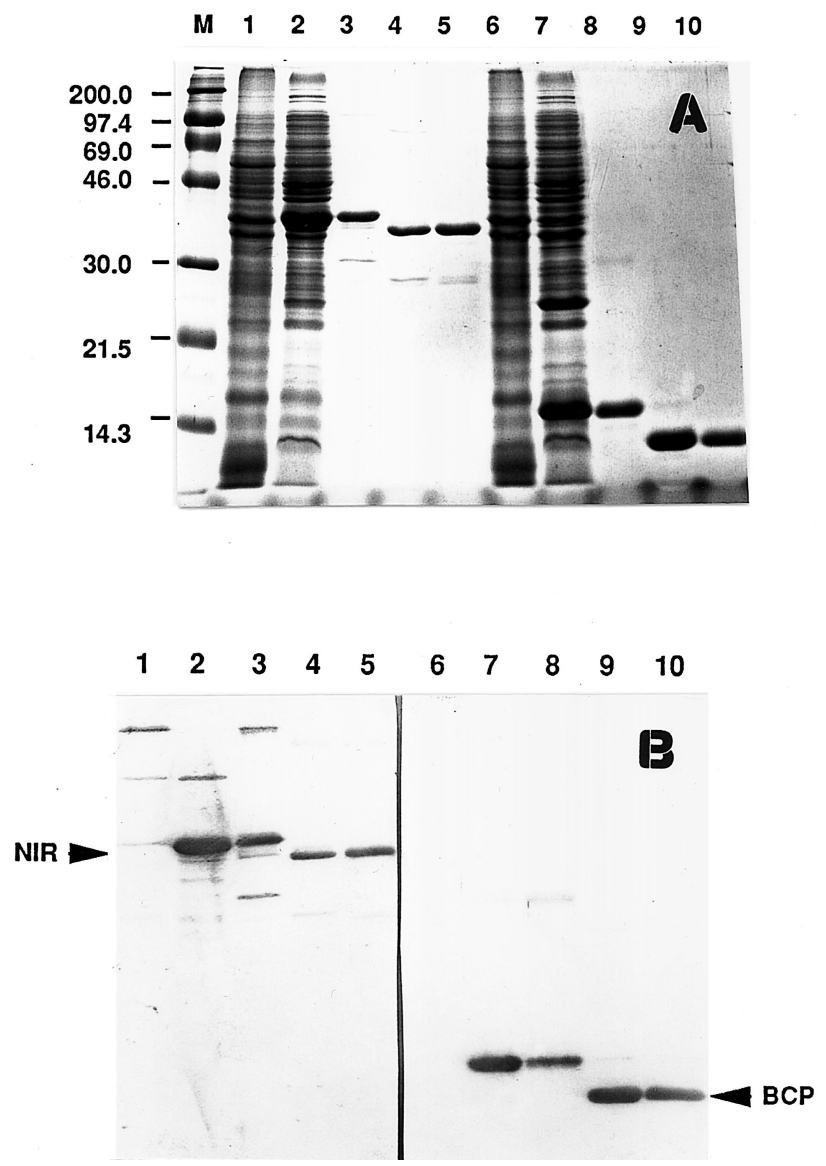

FIG. 2. The protein profiles of expressed NIR and BCP analyzed in SDS-PAGE (A) and Western blotting (B). M, protein markers with molecular weight in $\mathrm{kDa}$. Lanes 1 and 6, cell extract of the host $E$. coli M15. Lane 2, cell extract of E. coli M15 transformed with pQNIR and induced with IPTG. Lane 3, Ni-NTA resin purified recombinant NIR protein. Lane 4, enterokinase released NIR. Lane 5, native NIR protein as marker. Lane 7, cell extract of E. coli M15 transformed with pQBC3 and induced with IPTG. Lane 8, Ni-NTA resin purified recombinant BCP protein. Lane 9, enterokinase released BCP protein. Lane 10, native BCP protein.

Note: Both the NIR and BCP gene nucleotide sequences have been submitted to EMBL, the accession numbers are Z48635 (NIR gene) and Z48669 (BCP gene).

\section{ACKNOWLEDGMENTS}

This study was supported by grants from National Science Council of the Republic of China to Wen-Chang Chang (NSC83-0418-B-001-016-BA and NSC84-2311-B-001-051-BA) and by National Science Foundation of the U.S.A. (MCB 9105711) to W.J.P. and J.L.

\section{REFERENCES}

1. Payne, W. J. (1985) in Denitrification in the Nitrogen Cycle (Golterman, H. Ly, Ed.), pp. 47-65, Plenum, New York.

2. Kakutani, T., Watanabe, H., Arima, K., and Beppu, T. (1981) J. Biochem. 89, 463-472.

3. Liu, M. Y., Liu, M. C., Payne, W. J., and LeGall, J. (1986) J. Bacteriology 166, 604-608.

4. Godden, J. W., Turley, S., Teller, D. C., Adman, E. T., Liu, M. Y., Payne, W. J., and LeGall, J. (1991) Science 253, 438-442.

5. Inoue, T., Nishio, N., Kai, Y., Harada, S., Ohshiro, Y., Suzuki, S., Kohzuma, T., Shidara, S., and Iwasaki, H. (1993) J. Biochem. 114, 761-762. 
6. Kukimoto, M., Nishiyama, M., Murphy, M. E. P., Turley, S., Adman, E. T., Horinouchi, S., and Beppu, T. (1994) Biochemistry 33, 5246-5252.

7. Quertermous, T. (1990) in Current Protocols in Molecular Biology (Ausubel, F. M. et al., Eds.), pp. 5.8.1-5.8.5, Wiley, New York.

8. Hong, T. H., Chen, S. T., Tang, T. K., Wang, S. C., and Chang, T. H. (1989) J. of Immunological Method 120, $151-157$.

9. Bjerrum, O. J., and Schafer-Nielsen, C. (1986) in Electrophoresis (Dunn, , Ed.), pp. 315-327.

10. Ambler, R. P. (1977) in The Evolution of Metalloenzymes, Metalloproteins and Related Materials (Leigh, G. J., Ed.), pp. 100-118, Symposium Press, London.

11. Duffaud, G. D., Lehnhardt, S. K., March, P. E., and Inouye, M. (1985) Curr. Top. Membr. Transp. 24, $65-104$.

12. Petratos, K., Banner, D. V., Beppu, T., Wilkinson, K. S., and Tsernoglou, D. (1987) FEBS Lett. 218, $209-214$.

13. Kukimoto, M., Nishiyama, M., Ohnuki, T., Turley, S., Adman, E. T., Horinouchi, S., and Beppu, T. (1995) Pro. Engng. 8, 153-158.

14. Shaw, D. J., and Guest, J. R. (1982) Nucleic Acid Res. 10, 6119-6130.

15. Hussain, H., Grove, J., Griffiths, L., Busby, S., and Cole, J. (1994) Mol. Microbio. 12, 153-163. 